\title{
BIOLOGY AND ECOLOGY OF TICKS OF MEDICAL AND VETERINARY IMPORTANCE
}

\author{
Muhammad Usman Naseer ${ }^{1}$, Zia ud Din Sindhu' ${ }^{1 *}$, Muhammad Kashif Saleemi², Rao Zahid Abbas', Muhammad Kasib
} Khan $^{1}$, Bilal Aslam³, Muhammad Imran and Saima Yousaf ${ }^{4}$

'Department of Parasitology, University of Agriculture, Faisalabad, Pakistan

${ }^{2}$ Department of Pathology, University of Agriculture Faisalabad, Pakistan

3Institute of Physiology and Pharmacology, University of Agriculture, Faisalabad, Pakistan

${ }^{4}$ Department of Wildlife Management, Pir Mehar Ali Shah Arid Agriculture University, Rawalpindi, Pakistan

*Corresponding author: ziasandhu@hotmail.com; sandhu@uaf.edu.pk

\section{INTRODUCTION}

The economy of Pakistan is agriculture based and the livestock sector is one of the major subsectors of agriculture. According to the Pakistan Bureau of Statistics, the growth rate of the livestock sector in Pakistan was $2.58 \%$ during the last fiscal year 2020, which contributed $60.6 \%$ to the agriculture sector and $11.7 \%$ to the national GDP of the country. The gross value addition of livestock showed an increase of $2.5 \%$, as it increased from 1430 billion rupees in 2018-19 to 1466 billion rupees in 2019-20. The estimated population of different livestock species in Pakistan is as buffalo 41.2 million, cattle 49.6 million, sheep 31.2 million, goats 78.2 million, camels 1.1 million, horses 0.4 million, asses 5.5 million and mules 0.2 million (Zia et al. 2011). The survival of most of the livestock farmers in rural areas of the whole world depends on animal raising for their livelihood. They earn money by selling milk, meat, hides, and live animals. As the population of the developing world is increasing, the demand for animals and their products, especially food, is also increasing. Productivity of these animals, which ultimately ensures food security, is at risk by the infestation of various ectoparasites.

Ticks, flies, fleas, mites, and midges are important ectoparasites, out of which ticks are the most significant, because they cause a decrease in production by sucking blood (Elhaig et al. 2016; Wen et al. 2016). Ticks also indirectly affect animal production by transmitting various diseases (bacterial, viral, and protozoal) and toxins, and by causing tick paralysis (Rajput et al. 2005; Durrani et al. 2008; Zulfiqar et al. 2012). In this scenario, ticks and tick-borne diseases (TTBDs) are a huge threat to animal productivity, which ultimately threatens food security (Sibhatu et al. 2015). The ticks are included in the order Acarina and sub-order Ixodides, and are characterized by the presence of chelicerae and pedipalps on their mouthparts, while mandible and antennae are absent (Cheng 1964). Ticks are obligate blood sucking parasites that infest a wide range of hosts, including humans, with a worldwide distribution (Domingos et al. 2013; Hassan et al. 2013). They are the most important ectoparasites, affecting almost 8oo million cattle and sheep worldwide (Sutherst and Wilson 1986). Almost 900 species of ticks have been described and some of them are very common in transmitting various disease causing agents. Ticks are divided into three families: Argasidae (soft ticks) with 191 species, Ixodidae (hard ticks) with 701 species, and Nutalliellidae which consists of only one species (Pfäffle et al. 2013; Guglielmone et al. 2014).

Understanding the biology and ecology of the most prevalent ticks of medical and veterinary importance will help to design effective tick control and eradication programs. This chapter describes the important biological and ecological factors, which play a vital role in the prevalence of TTBDs.

\section{Prevalence of TTBDs in Pakistan}

In the livestock industry, almost $80 \%$ of the cattle population is infested with TTBDs worldwide (Ghosh et al. 2006), including Pakistan. Direct losses caused by ticks are the damage of skin by wound opening that leads to paralysis and secondary bacterial infections. Indirect effects of TTBDs are even greater than the direct losses because of their ability to act as vectors of various diseases, such as Babesiosis and Theileriosis (Jongejan and Uilenberg 2004; Schroder and Reilly 2013). Ticks have a unique ability that they can survive for three years without food, however, they are not in a position of oviposition during this time because they need to be engorged for this phenomenon. Ticks affect their hosts in many ways, such as reduction in growth rate and milk production, damage to hides and transmission of disease causing organisms that can cause paralysis and injuries. The underlying tissues and the host's integument are severely damaged by tick bites.

To date, many studies have shown that more than $80 \%$ of buffaloes and cattle in Pakistan are exposed to two major species of ticks (Sajid et al. 2008; Iqbal et al. 2013; Farooqi et al. 2017; Rehman et al. 2017) i.e. Rhipicephalus (R.) and Hyalomma (Hy.), which transmit Theileria, Babesia and Anaplasma species to buffaloes and cattle (Jabbar et al. 2015; Karim et al. 2017). Many studies have found that $H y$. anatolicum is the most abundant tick species in Pakistan (Sajid et al. 2009; Karim et al. 2017; Rehman et al. 2017), followed by $R$. microplus (Ghafar et al. 2020). Karim et al. (2017) reported 17 hard tick species from Pakistan, which include Hy. anatolicum, Hy. bispinosa, Hy. isaaci, Hy. hussaini, Hy. dromedarii, Hy. turanicum, Hy. kumara, Hy. scupense, Haemophysalis (Ha.) cornupunctata, Ha. kashmerensis, Ha. sulcata, Ha. montgomeryi, R. microplus, 
$R$. sanguineus, $R$. annulatus, $R$. haemaphysaloides and $R$. turanicus. The same study reported the highest diversity of ticks in Azad Kashmir and Baluchistan, most probably due to nomadic lifestyle of the people in these regions (Karim et al. 2017). Ticks are equally important in the case of equines, because they cause blood loss and transmit various diseases, such as Equine Granulocytic Anaplasmosis, Piroplasmosis and Equine Lyme Borreliosis (Sigg et al. 2010). Hemolytic conditions can be observed in horses, donkeys, mules, and zebras due to equine tickborne hemoparasitic diseases (Traub-Dargatz et al. 2010).

It has been reported in many studies that ticks are the most prevalent during the summer months of June, July and August (Kosar 1965; Khan 1967; Durrani 1992; Sajid et al. 2009) and comparatively absent during the winter months of December, January, and February (Sajid et al. 2009). The summer temperature of Pakistan, specifically Punjab Province, remains between $38-48^{\circ} \mathrm{C}$, which is ideal for the reproduction, development and growth of ticks (Sajid et al. 2009). This monthly variation is also justified by the questing activity of ticks. Lower temperatures and higher altitudes delay the activity of ticks and vice versa (Jouda et al. 2004). The males have a higher prevalence of ticks than females (Sajid et al. 2009) and the possible reason behind this could be that the males receive less attention from the farmers because of their interest in the dairy animals. European breeds (Jersey, Friesen and their crosses) are relatively more affected ticks. Their denser and longer hairs are considered to be the factors for greater tick infestation (Verissimo et al. 2002; Sajid et al. 2009). Predilection sites for the larvae of Boophilus microplus include dewlap, axillae, flank and escutcheon (Reik 1962), while for Hyalomma these sites are lips of vulva, inside of thighs, ears and neck (Mattioli et al. 1997). Cattle are found to be more prone to the tick infestation than buffaloes due to swamp habitat and thicker skin of buffaloes as compared to dry habitat and thinner skin of cattle (Sajid et al. 2009).

\section{Morphological Features}

The ticks have a segmented body but these are not clearly visible. They possess two body parts namely; the capitulum or gnathostoma and the idiosoma. The capitulum is comprised of basis capituli, which is heavily sclerotized, bearing mouthparts (Gregson 1960). The mouthparts are located on gnathostoma, and comprise three different types of structures. First is a toothed and elongated hypostome, which is located on the ventral side of the mouth. The hypostome projects anteriorly from its free end. The second part is a pair of chelicerea, present on each dorsolateral surface of the hypostome. The basis capitulum is connected to a sheath that is encasing each chelicera. Each chelicera contains teeth on its outer surface. The third part is a pair of pedipalps or palpi, which arise from the basis capitulum at the anteroventral margins. The ticks of family Ixodidae have rigid palps and they are associated with the hypostome, however, the Argasidae have flexible pedipalps associated with the hypostome. Family Argasidae ticks possess a leathery integument that covers the whole dorsal surface. This cuticle contains ornamentations of granules, tubercles and even circular discs in some cases. Three pairs of legs are present in all the tick larvae; however, a fourth pair is found after the molting of the larval stage in the nymph and adult tick stages (Cheng 1964).

The adult females possess a scutum, which is a rigid area and a genital pore is ventrally situated between the third or fourth pair of legs. Nymphal stages can be differentiated from adult females because they possess a size equal to half of the adult females. Additionally, scutum is present but genital pore is lacking. If it is confirmed that the specimen is adult, the next part for examination is the position of a cuticular fold near the anus, called the anal groove. The anal groove may be present in front of or behind the anus. Palps are sensory in their function and are supported by the basis capituli. The shape, length and width of these palps is also used to differentiate between different genera of ticks. The term 'decorated' (ornate ticks) is used for ticks when their scutum appears to be metallic, patterned or brightly colored. These features are useful in the identification of different genera of ticks and then their further evaluation at the species level (McGarry 2011).

\section{Life cycle and Behavior of Ticks}

All the ticks are obligate parasites of vertebrate animals, and are characterized by a complex life cycle. The life cycle of ticks includes hatching of eggs and development into larvae, then after feeding, the larvae drop on the ground and molt into nymphs. The nymphs need to find a suitable host for further feeding and then again return to the ground for further molt, resulting in an adult. The adult will also feed and mate, while the females will lay a huge clutch of eggs, which are left in protected sites like decaying vegetation, where survival is ensured by the high relative humidity (Kahl et al. 2002). Ticks take a blood meal during every active stage and ingest a sufficient quantity of blood, which is necessary for oviposition and molting. The mating phenomenon takes place on the host in most of the tick species, however, some species mate in vegetation during questing for a host. Most of the ticks have a three-host life cycle, but some species possess two hosts, where feeding of larvae and nymphs occurs on the same host and molting does not occur at the ground. Some ticks of family Ixodidae have a single host life cycle, where each step of feeding, molting and mating occurs on the same host (Estrada-Pena and de la Fuente 2014).

The search for a host by the active stages of ticks is known as questing or host-seeking behavior (Estrada-Pena et al. $2013 \mathrm{~b}$ ), which is an important process in the life cycle of a tick that also affects the pathogen transmission ability of ticks. Before starting to quest, most of the ticks are found in the lower layers of vegetation in an inactive form, and this process is triggered by a unique combination of photoperiod and climate, influenced by the light and darkness hours in a day (Belozerov 1982). Photoperiod acts on the molting stages of ticks, causing activation or delay in the molting until the availability of favorable 
conditions, while in the case of questing stages, the onset of activity can be initiated or delayed. Although the role of photoperiod has been ignored during the investigation of tick seasonal activities, this single factor has a strong impact on the epidemiology and transmission of viral diseases (Estrada-Pena et al. 2013a). Ticks have an interesting phenomenon that they detect their host by sensing carbon dioxide and if this phenomenon exists in various tick species, it is an indication that the capability of host detection was present in the ancestral tick lineage (Mans 2014).

During questing and development, ticks need a relative humidity of more than $80 \%$ or longer periods because they are exposed to desiccation during these stages (Gray 1998). Questing of ticks can be continued for several months but they have to refill their water reserves by frequent visits down to the base from surface vegetation. Water is obtained from sub-saturated air, where they secrete a hygroscopic fluid from salivary glands on the external mouthparts and then the water-enriched fluid is re-ingested (Kahl and Knülle 1988). The time taken by the tick during the questing phase depends upon some factors including micro-climatic conditions, host-seeking success and the energy reserves available for replenishment of water. The length of the questing period for individual ticks can vary from several weeks to months in a conducive environment and is stage dependent because adults quest for the longest periods, while larvae quest for the shortest. Different factors like relative humidity, temperature, sunshine and rain are important for questing behavior and vary in different habitats, affecting energy depletion and water balance, and ultimately affect the survival of ticks (Gray et al. 2016).

Seasonal climate change and regional events of weather are the consequences that restrict questing in a defined period in temperate regions. The contact rates between ticks and their hosts are controlled by specific principles: the frequency of contacts is directly related to the abundance of hosts and ticks, ultimately questing of ticks will occur in a lesser time and; the higher host density will also help to reduce tick mortality because of the availability of abundant suitable hosts.

\section{Physiology of Ticks}

\section{Off-host osmoregulation}

This is a matter of debate that how do the hard ticks survive for several months when they are off-host? Family Ixodidae share a common feature of integument with insects that is impermeable to water. Another common property between ticks and insects is that they can absorb water vapors from the environment when the following two conditions are fulfilled: (i) there should be a certain degree of dehydration and (ii) the level of relative humidity should be specific in the atmosphere. The value of critical equilibrium humidity (CEH) should be in a range of $80-95 \%$ and it is species specific. However, in some insects, the level of CEH can be lowered up to $50 \%$ (Edney 1977). This value ranges from $75-95 \%$ in ticks, which is dependent on the developmental stage and tick species (Needham and Teel 1986; Gaede and Knulle 1997; Yoder et al. 2006). Ticks have to utilize the metabolic energy for taking up the water vapors from the atmosphere if the level of relative humidity is less than $100 \%$ (Edney 1977). The uptake of water vapors is best observed in unfed ticks; however, this phenomenon can also be studied in the larvae and nymphs of fully engorged ticks when they are absorbing water vapors from the unsaturated atmosphere.

For water uptake, a major role is played by the salivary glands and this process occurs through the oral cavity (Rudolph and Knulle 1974). If the atmosphere has an increased level of CEH, a tiny droplet of saliva is secreted by the tick on mouthparts. As the saliva is hygroscopic, atmospheric water vapor is condensed on it. This enlarged droplet is now swallowed by the tick, a fresh aliquot is secreted and this process is repeated until the tick attains its normal hydration level. This is called rehydration saliva and is secreted by the type-I acini of salivary glands. These acini help in the processes of active transport system because they have the ultra-structural properties of tissue functioning (Fawcett et al. 1986). Some organic solutes which are still unknown, are assumed to be responsible for the hygroscopic nature of saliva (Knulle and Rudolph 1982; Needham and Teel 1986).

\section{On-host Osmoregulation}

Blood sucking insects maintain the osmotic equilibrium by using Malpighian tubules for excreting excess fluid from the blood meal (Maddrell 1981). Like insects, the ticks of families Ixodidae and Argasidae also use Malpighian tubules for excretion of nitrogen, these two major tick families have developed a unique system to deal with the excess fluid of blood meal. For this purpose, salivary glands are used by the hard ticks and coxal organs by the soft ticks. In the case of hard ticks, salivary glands are only used by the female ticks. Males take only a small amount of blood meal, thus the osmotic stress is not significant in them and up till now, no one has explored osmoregulation in feeding males. Female salivary glands develop ultra-structural properties during feeding, however, this feature is absent in males (Kaufman 2010).

\section{Blood Feeding}

Hematophagy (blood feeding) is a vital physiological process for ticks to maintain their nutrient requirements for reproduction and development. Ticks have a unique blood feeding process compared to other hematophagous arthropods. Hard ticks feed blood once in their lifetime and females lay down a large number of eggs and die after several days of egg laying (Coons and Alberti 1999). Feeding of ticks has been divided into three stages: attachment, slow feeding and feeding (Kemp et al. 1982; Anderson and Magnarelli 2008). The attachment phase further includes multiple steps including identifying a vertebrate host, penetration deep into the dermis through barbed mouthparts, a secure attachment through the 
hypostome encasement, and provision of a suitable environment during a blood meal to transmit the pathogens (Alekseev et al. 1995; Anderson and Magnarelli 2008).

\section{Feeding Patterns of Families Ixodidae and Argasidae}

Ticks ingest the blood and tissue fluid by anchoring through a mouthpart structure, called hypostome, which creates a lesion during feeding. Argasidae have a rapid speed of blood feeding and they feed only on tissue fluid. On the other hand, Ixodidae complete the feeding process in several days and they feed on blood, lysed tissues and lymph around the mouthparts. The best time for the transfer of pathogens is during feeding because cutaneous damage is caused to the skin during this time. Stages of blood feeding in the life cycle of ticks include small larvae, nymphs and adult females (McGarry 2011). Slow feeding of Ixodidae female ticks takes 6-9 days in the first stage, which is followed by the detachment stage that occurs 1224 hours before detachment from the host. Only females that take part in mating can go for a rapid engorgement period, indicating an uncharacterized mechanism of physiological control (Sojka et al. 2016). The feeding duration of Ixodidae varies greatly between and within species, and ranges from 3-5 days for larvae, 4-8 days for nymphs and 5-20 days for adult females. Interestingly, males also attach to the host's skin but only feed a very small amount of blood and enlarge insignificantly. For initial 24 hours, females remain flat and then start to swell gradually with blood, leading to full engorgement after 48 hours as the rate of blood intake increases rapidly. Hyalomma and Amblyomma tick species ingest larger quantities of blood from animals up to $2 \mathrm{ml}$, increasing in weight from $0.04 \mathrm{~g}$ to $4.0 \mathrm{~g}$ and size from $10 \mathrm{~mm}$ to $25 \mathrm{~mm}$ (Wall and Shearer 2001). In animals, Ixodidae have specific sites for blood feeding, however, in humans, they can be found on any part of the body (Felz and Durden 1999) and can feed un-noticed (Hatwick et al. 1978; Krinsky 1983).

Ticks have the ability to feed on the host un-noticed for extended periods due to highly adaptive mechanisms of feeding (Binnington 1978; Binnington and Stone 1981). Numerous proteins are produced by the tick salivary glands to create the stable environment for feeding through alteration of the host's immune response, haemostasis and inflammation (Francischetti et al. 2009; Mans 2011; Fontaine et al. 2011). Depending on the species, most of the adult ticks remain attached to the host for 7-21 days, where a cement cone is required for a firm attachment. Mouthpart is protected from the immune system of the host by the cement cone (Alekseev et al. 1995) and helps the ticks to enter the host's dermis. Different tick species secrete a proteinaceous matrix from cement cone, both by long mouthparts (longirostra) and short mouthparts (brevirostra) (Kemp et al. 1982). In response to the feeding of ticks, the host reacts by vasoconstriction, activation of the coagulation cascade, formation of a hemostatic plug, inflammatory responses and tissue remodeling, leading to the wound healing. This leads to the rejection of tick feeding with detrimental effects on tick reproduction and viability. However, ticks complete their successful blood meal because various biologically active molecules are present in salivary glands, displaying antiplatelet, anticoagulation, immunemodulatory, vasodilatory and anti-inflammatory activities.

\section{Digestion of Blood Meal}

The process of blood digestion is different in ticks than that of hematophagous insects where digestion of proteins takes place rapidly in the gut lumen. Digestion is an intracellular process in ticks that proceeds slowly for which the optimum $\mathrm{pH}$ of proteases is 3 and for gut contents, optimum $\mathrm{pH}$ is 6.5. Three different phases are involved in tick feeding, namely the preparatory phase, growth phase and expansion or rapid engorgement phase. These phases are involved in the digestion process, with the exception of the preparatory phase which lacks digestion. Continuous digestion starts in the growth phase, followed by the expansion phase that involves a slow digestion process. After detachment, the process of slow digestion starts again and it continues till the end of oviposition (Friedhoff 1990). The protease activity is decreased (only 10\%) at the end of the rapid engorgement phase. Thus, the hostile environment is no more available in the tick gut because proteases are intracellular and cannot work at the $\mathrm{pH}$ of vertebrate blood that entered the tick gut. In Argasidae ticks, concentrated blood meal is stored as a food reserve, however, the process of blood digestion is similar to that of Ixodid ticks. Since the feeding process is rapid in Argasidae, the following steps are involved in the blood digestion; no digestion phase, rapid and slow digestion phase (Akov 1982; Coons et al. 1986). The process of blood protein digestion is rapid in the lumen of the gut and is assisted by alkaline serine proteases in most hematophagous insects (Briegel and Lea 1975). On the contrary, ticks have a slower process of blood digestion in gut cells inside the acidic vesicles (Grandjean and Aeschlimann 1973).

\section{Harmful Effects of Ticks}

Following are some direct and indirect methods by which ticks may harm the animal and lead to production and economical losses to the farmers.

\section{Tick Paralysis}

Although ticks cause many problems through direct effects on the host, they are also harmful indirectly by transmitting many disease causing organisms. They transfer toxic substances through their saliva while feeding steadily on the host; these result in severe clinical cases, ultimately leading to toxicosis and paralysis (Jongejan and Uilenberg 2004; Estrada-Pena and Mans 2014). Salivary secretions of ticks play an important role in the transmission of diseases because of the injection of toxic compounds, causing flaccid paralysis and affect the general metabolism (Cupp 1991). Salivary neurotoxins, which are transferred to the host during the feeding of 
ticks, are considered to be responsible for paralysis. It has been suggested that toxin generation is associated with the prevention of blood coagulation, reduction in host mobility and excretion of local anesthesia during feeding (Stone et al. 1989). Ticks remain attached to their host for longer period because inflammatory and immune responses are suppressed by the components of tick saliva. These toxins in the salivary secretions are responsible for the destruction of host tissues (Bowman et al. 1997). Many cases of heavy mortalities have been recorded due to tick toxins and the best example is ascending motor paralysis due to ticks in vertebrate hosts (Estrada-Pena and Mans 2014). Some species of ticks secrete toxins that affect the nervous system of the host. Only small quantities of these toxins are secreted by larval and nymphal stages; thus paralysis is caused by adult female ticks, which secrete a sufficient amount of toxins to the host. The terminal part of the motor nerve fiber is altered by these toxins, which further leads to the failure of animal mobilization.

Paralysis usually continues during the presence of ticks because this is the phenomenon of chemical induction of toxins by the ticks. Thus, the symptoms of paralysis are diminished quickly after the removal of ticks from the host. However, in certain cases, there are chances of development of profound paralysis, which can also become fatal before the awareness about the presence of ticks. As the tick attach to their host, the symptoms of weakness may take five days to set in. Effects of toxins can be metabolized rapidly or diminished within 12-24 hours after the removal of ticks (Mondal et al. 2013). Paralysis through tick bites is characterized by the loss of sensation and muscular functions; and even in some cases, the respiration is affected that may lead to death. Thus, further investigation is required for molecular characterization and identification of toxins causing paralysis, which will help to sort out the mysterious structure of these potent toxins. Many low molecular weight effectors and proteins are present in the tick saliva to target the host defense mechanism. Tick saliva with abundant proteins offers a great opportunity to discover various pathways of effectors targeting specific physiological pathways of mammals.

\section{Transmission of pathogens}

The importance of ticks for wildlife and livestock can be realized by the fact that they pierce the skins of hosts, resulting in the transmission of many disease causing agents as vectors (Allen 1994). In this scenario, a few examples of tick-borne diseases can be quoted, which include Bovine Anaplasmosis caused by Anaplasma marginale (Kocan et al. 2010), Babesia bigemina causing the disease African red water or Bovine Babesiosis (Bock et al. 2004; Suarez and Noh 2011; Farooqi et al. 2017), Ehrlichia rumanntium causing heart-water (Allsopp 2010) and strains of Theileria parva causing East Cost Fever, Corridor Disease and January Disease (Bishop et al. 2004). The carriers of these diseases are mostly the wildlife species, with an additional importance to cause the zoonotic diseases in humans (Smith and Parker 2010), indicating their great medical importance. Salivary secretions transmit most of the pathogens, although the Argasidae can transmit vectored pathogens through coxal fluid, which is used for irrigation of feeding lesions (Burgdorfer 1951). The efficacy of transmission of a diseased pathogen by ticks to the host can be determined by the amount of secreted saliva because salivary glands are the most important route of pathogen transmission (Kaufman and Phillips 1973; Koch and Sauer 1984). After feeding on a blood meal, the pathogens reside in the gut contents with ingested blood, and showing different mechanisms to pass through the membranes of the gut. Laboratory trials have indicated that certain pathogens may find their way to the gut cells through the expression of molecules that allow recognizing the specific receptors in the cell membrane (de la Fuente et al. 2001).

Some well-known tick species transmit pathogens to humans and they have been very well studied due to their public health significance. In this case, an example of Hyalomma genus can be given, because it transmits the most important disease, Crimean Congo Hemorrhagic Fever (CCHF) to humans, thus researchers have focused their attention for its investigation (Hoogstraal 1979). In Pakistan, the first case of CCHF was reported in 1976 and has become endemic (Alam et al. 2013; Ansari et al. 2018). This virus is particularly important in people, who are closely related to livestock activities (Lugaj et al. 2014) and Pakistan being an agricultural country, is at risk of this vector-borne disease. As Hyalomma tick species are very common in livestock in Pakistan, this is a major threat for animals and humans (Rehman et al. 2017). However, some tick species transmit pathogens in cryptic cycles without their direct involvement, and ultimately pathogen transmission becomes perpetuated in the ecosystem. The active foci of pathogen transmission can be sustained in the ecosystem by these cryptic cycles. Thus, the clinical cases will not be noticed in the human population because of the absence of vector linkage between reservoir hosts and humans.

Trans-ovarial and Trans-stadial Transmission

Epidemiologically, ticks have two important events to maintain the transmitted pathogens. Ticks feed only once at each stage, the pathogen needs to persist at every stage after molting, so that it may be passed to the next vertebrate cohort by an infective bite. This course of the stage to stage transmission is called trans-stadial passage. In this phenomenon, tick feeds on a reservoir host and acquires a pathogen, thus the pathogen has to further persist in the newly molted stage of the tick. The vertical or transovarial passage is another important feature involved in the transmission of a pathogen by ticks. The tick acquires a persisted pathogen, while engorged female ticks transfer it to the cohort of eggs. This phenomenon is considered to be responsible for the transfer of many pathogens to unaffected hosts and the new generation of ticks. The rate of transfer of pathogens to the next generation of ticks is a species specific mechanism and 
both phenomena of pathogen transfer are dependent upon this mechanism (Hartemink et al. 2008).

The mechanism of transmission and maintenance of pathogens by the ticks and their hosts cannot simply be determined by the field studies, because such studies only report a small sequence of nucleic acids from a big population of ticks. Complementary laboratory studies should also be adopted as an essential part to testify the hypothesis made in the field trials. The ticks should possess the following qualities to be a successful vector of pathogens, (a) feeding on infectious vertebrates, (b) pathogen acquiring during feeding on blood meal, (c) maintenance of pathogen during single or more transstadial molts, and (d) transmission of the pathogen to previously unaffected hosts (Kahl et al. 2002). The status of the carrier or non-carrier state of the host is determined by the feeding of ticks and transmission of the pathogen to the host. According to this definition, pathogen carrying hosts are called the carrier hosts, however, it is not necessary that the carrier hosts are infected by the ticks, thus infectivity status must be defined by the terms reservoir and non-reservoir. Non-reservoir hosts are those which are unable to transmit the pathogens to uninfected ticks (Estrada-Pena and de la Fuente 2014).

It is suggested that if the tick species responsible for pathogen transmission to wild vertebrates are present in the ecosystem, the presence of pathogens will go unnoticed until the availability of ticks that will link it to humans. Furthermore, seasonality and abundance of hosts, regional weather and variations in the abundance of ticks can change the epidemiological landscape by their interaction. Therefore, a specific mechanism of pathogen transmission in a community of ticks, hosts and pathogens cannot be implemented in another community because these are realized as regional or local processes.

\section{Host Immune Response against Ticks}

The host immunity against ticks was first described in 1918, but little was known during 1918-1973 about the bovine immunity towards ticks. However, Bos indicus cattle were considered to be resistant against ticks when compared with Bos taurus cattle. It has been described that immediately after the feeding of ticks, cellular density is increased up to $80 \%$ because of the arrival of the vasoactive amines at the feeding site. Immunity of the host against ticks has been described in many studies due to the active role of basophil derived mediators such as (i) resistant animals had twice the level of tissue histamine as compared to susceptible animals (Willadsen et al. 1979; Wikel 1982), (ii) histamine injection caused the tick withdrawal or mortality at the attachment sites along with the interruption in the feeding when histamine was added to the artificial media, and (iii) histamine receptor antagonist caused the reduced skin reactivity and resistance (Tatchell and Bennett 1969; Bagnall 1975; Brossard 1982; Wikel 1982).

Histopathologically, it has been observed that tick feeding sites possess neutrophil infiltration, which is accompanied by eosinophil response as the cutaneous cellular mechanism in naive animals. The restricted pathological lesion to the site of feeding is due to the formation of a feeding cavity that leads to hemorrhages as the feeding process advances. Perivascular cuffing is caused by neutrophils in the vessels of the lower dermis. Additionally, a little degranulation is also observed because basophils are accumulated at the border of the epidermis and dermis (Brown 1988). Microscopically, feeding sites have been observed to possess intraepidermal vesicles. Here, leukocytes showed intense cellular response adjacent to the tick's hypostome that mainly contains basophils. Interestingly, circulating leukocytes consist of only $1 \%$ basophils because they are not the normal residents of the majority of vertebrate tissues (Schermer 1967; Bloom and Fawcett 1975), however, their number can increase up to $500 \%$ in the hosts affected by ticks (Gordon and Allen 1979; Brown and Askenase 1982). It has been suggested that a specific immunological response involving T-cells and antibodies is the reason for the accumulation of these cells in tissues (Askenase 1977).

The hemostasis phenomenon is triggered by vascular injury, accompanied by a triad of platelet aggregation, blood coagulation and vasoconstriction. The mechanism of hemostasis is started within few seconds of tissue injury. Scar formation is induced by the mechanism of tissue repair, which starts with the injury and continues for several days. Cellular and humoral immune responses are triggered by the immune system that causes modification at the site of tick feeding. Such types of immune responses are immediate, as seen in antigen/antibody/complement reactions, or may take longer periods in their occurrence similar to cellular reactions where leukocyte infiltrates are formed like basophilic infiltrates (Allen 1973). As Argasidae and Ixodidae take time from few hours to several days during feeding, various feeding strategies are involved to influence the host immune response. However, the activation of the host immune system depends upon many factors, such as health status, the genetic background of the host and species of the ticks and hosts involved. Many authors are of the view that the role of histamine in the immunity of the host against ticks is secondary because basophil derived mediators are considered to play a major role in this immune response. Furthermore, ticks have the ability to induce immunomodulation in the host immune response because of the presence of many immunomodulators in their salivary glands. Thus, there is a need of deep understanding and investigation of the tick salivary glands having biologically active molecules which they use to inactivate the host resistance against ticks.

\section{Factors Affecting Tick Abundance and Distribution}

\section{Climate Change}

In Pakistan, ticks are most prevalent during the summer months and comparatively absent during the winter months (Sajid et al. 2009). The primary factor in the prevention of tick distribution is considered to be climate 
change, given that the tick distribution is not necessarily affected by its hosts. However, broad scale factors about tick distribution have yet not been established (Cumming 2002). It has been suggested that an increase in the temperature will lead to an increased tick distribution, particularly in endemic areas. Additionally, this change can cause several implications related to tick infestation and incidence, and control of tick-borne diseases. In this regard, the example of South Africa can be quoted, where increased temperature caused the displacement of $R$. decoloratus with the Asian intruder $R$. microplus (Tønnesen et al. 2004; Nyangiwe et al. 2013). This species of Ixodidae is now present in all of Africa with warm and humid climates, except for extremely cold areas. Similarly, another tick species, Amblyomma herbraeum, had its natural habitat of warm and moist coastal areas (Coetzer et al. 1994), but now its distribution has also been reported in the semiarid areas (Nyangiwe et al. 2011). This changed distribution of bont tick has been hypothesized due to intense drought periods in highlands areas, as happened in Zimbabwe (Estrada-Pena et al. 2008).

Tick populations are also affected by short term alterations in local weather conditions. For instance, variations are expected in the development rates of tick populations during milder temperatures in winter and autumn. Similarly, the normal temperature in the winter season, which is high enough to stimulate questing, ticks may quest for the host. These factors must be considered while predicting the tick distribution because ticks have an increasing trend towards those areas which were previously uninhabited.

\section{Nidicolous and non-nidicolous Ticks}

On the basis of mobility and site of living, ticks are divided into two types; including nidicolous (nestdwelling) and non-nidicolous (field-dwelling). Thus, ticks with nidicolous behavior would have a stronger population structure (Anderson and Magnarelli 2008). The movement of nidicolous ticks is usually low because they occupy places having the availability of favorable habitats and food (Lane et al. 1999). On the contrary, nonnidicolous ticks have a more widespread range with different time alterations, including the time spent free in the environment and the time spent on the host during feeding. Field dwellers have the opportunity to disperse in wide ranges because they are not limited to seek sites near nests. These are the reasons which suggest that nidicolous ticks will have a stronger population structure compared to non-nidicolous. It is further suggested that the ticks in one nest will have more association than those in another nest (Araya-Anchetta et al. 2015).

\section{Other Vital Factors}

The abundance and distribution of ticks are also affected by some other vital factors, including availability of alternative hosts, grazing management, natural resistance and acaricide use (Cumming 2002). Alternative hosts gain importance in the absence or sparse availability of natural hosts, influencing the tick distribution. Alternative hosts also act as a source of the movement of ticks to different habitats and thus, increasing the tick distribution (RuizFonsa and Gilbert 2010). Tick distribution can also be affected by the prolonged use of acaricide treatments, along with the absence of alternative hosts (Norval et al. 1994). Microclimate in the lowest vegetation layers is another important factor to regulate the tick abundance (Belozerov 1982). In temperate regions, longer periods of summer coupled with an increased temperature and high desiccating power of the air undoubtedly cause an increased mortality rate in the questing or molting stages of ticks. On the other hand, extremely low temperatures during the winter season can also induce significant mortalities in ticks. However, it is a well-known fact that when snow covers the ground, it provides a protective effect for ticks overwintering in the ground during low temperatures (Childs and Paddock 2003).

In Pakistan, tick density can be reduced by the modification of habitat and pasture management with possible methods like drainage, herbal treatment, controlled burning, removal of leaf litter and clearing of bushes mechanically. Habitat alteration can also result in the change of availability of the host for ticks. However, these methods of reducing tick density can only be applicable for shorter period, and additionally, the majority of these methods are labor-intensive and require periodical repetition. Furthermore, altered habitat may lead the farm animals at risk of tick-borne diseases posed by the ticks that came from other habitats, thus, this habitat modification is not always favorable.

Ultimately, tick control strategies in Pakistan need to be revolved around alternate methods, minimizing chemical residues, preventing production losses, reducing chemical treatment and reducing the number of ticks to acceptable levels. Although various studies have been conducted on TTBDs and sufficient data has been generated since the last 45 years, still there is need to focus on systematics, functional genomics, proteomics and transcriptomics in Pakistan.

\section{REFERENCES}

Akov S, 1982. Blood digestion in ticks. In: Obenchain FD Galun R (editors), Physiology of Ticks. Pergamon Press, Oxford, UK; pp: 197-211.

Alam MM et al., 2013. Genetic analysis and epidemiology of Crimean Congo Hemorrhagic fever viruses in Baluchistan province of Pakistan. BMC Infectious Diseases 13: 201.

Alekseev AN et al., 1995. Bacteriocidal qualities of Ixodid tick (Acarina: Ixodidae) salivary cement plugs and their changes under the influence of a viral tick-borne pathogen. The Journal of Medical Entomology 32: 578-582.

Allen JR, 1973. Tick resistance: Basophils in skin reactions of resistant guinea pigs. International Journal of Parasitology 3: 195-200.

Allen JR, 1994. Host resistance to ectoparasites. Revue Scientifique et Technique 13: 1287-1303. 
Allsopp BA, 2010. Natural history of Ehrlichia ruminantium. Veterinary Parasitology 167: 123-135.

Anderson JF and Magnarelli LA, 20o8. Biology of ticks. Infectious Disease Clinics of North America 22: 195215.

Ansari JA et al., 2018. Crimean Congo heomrrhagic fever in Pakistan: Case control study, 2012-2015. Pakistan Journal of Public Health.

Araya-Anchetta et al., 2015. Thirty years of tick population genetics: A comprehensive review. Infection, Genetics and Evolution 29: 164-179.

Askenase PW, 1977. Role of basophils, mast cells, and vasoamines in hypersensitivity reactions with a delayed time course (Part 1 to 4 ). Progress in Allergy 23: 199-320.

Bagnall BG, 1975. Cutaneous immunity to the tick Ixodes holocyclus. Ph.D. Dissertation, University of Sydney, Australia.

Belozerov VN, 1982. Diapause and biological rhythms in ticks. In: Obenchain FD and Galun R (editors), Physiology of Ticks. Pergamon Press, Oxford, UK; pp: 469-500.

Binnington KC, 1978. Sequenctial changes in salivary gland structure during attachment and feeding of the cattle tick, Boophilus microplus. International Journal of Parasitology 8: 97-115.

Binnington KC and Stone BF, 1981. Developmental changes in morphology and toxin content of the salivary gland of the Australian paralysis tick Ixodes holocyclus. International Journal of Parasitology 11: 343-351.

Bishop R et al., 2004. Theileria: Intracellular protozoan parasites of wild and domestic ruminants transmitted by Ixodid ticks. Parasitology 129: 271-283.

Bloom W and Fawcett DW, 1975. A Textbook of Histology. WB Saunders, Philadelphia, PA, USA.

Bock et al., 2004. Babesiosis of cattle. Parasitology 129: 247-269.

Bowman et al., 1997. Tick saliva-recent advances and implications for vector competence. Medical and Veterinary Entomology 11: 277-285.

Briegel H and Lea AO, 1975. Relationship between protein and proteolytic activity in the midgut of mosquitoes. Journal of Insect Physiology 21: 1597-1604.

Brossard M, 1982. Rabbits infested with adult Ixodes ricinus L.: Effects of mepyramine on acquired resistance. Experientia 38: 702-704.

Brown SJ and Askenase PW, 1982. Blood eosinophil and basophil responses in guinea pigs parasitized by Amblyomma americanum ticks. The American Journal of Tropical Medicine and Hyiene 31: 593-598.

Brown SJ, 1988. Highlights of contemporary research on host immune responses to ticks. Veterinary Parasitology 28: 321-334.

Burgdorfer W, 1951. Analyse des Infektionsverlaufes bei Ornithodorus moubata (Murray) und der naturlichen - Ubertragung von Spirochaeta duttoni. Acta Tropica 8: $193^{-262 .}$

Cheng TC, 1964. The Biology of Animal Parasites. W.B. Saunders Company, Philadelphia, USA.
Childs JE and Paddock CD, 2003. The ascendancy of Amblyomma americanum as a vector of pathogens affecting humans in the United States. Annual Review of Entomology 48: 307-337.

Coetzer JAW et al., 1994. Infectious Diseases of Livestock with Special Reference to Southern Africa. Oxford University Press, Cape Town.

Coons PM et al., 1986. Blood meal digestion in ticks. In: Sauer JR Hair JA (editors), Morphology, Physiology, and Behavioral Biology of Ticks. Wiley \& Sons, New York, USA.

Coons LB and Alberti G, 1999. Acari: Ticks. In: Harrison FW Foelix RF (editors), Microscopic Anatomy of Invertebrates, Chelicerate Arthopoda. Wiley-Liss, New York, USA; pp: 267-514.

Cumming GS, 2002. Comparing climate and vegetation as limiting factors for species ranges of African ticks. Ecology 83: 255-268.

Cupp EW, 1991. Biology of ticks. Veterinary Clinics of North America: Small Animal Practice 21: 1-26.

de la Fuente J et al., 2001. Evolution and function of tandem repeats in the major surface protein ra of the ehrlichial pathogen Anaplasma marginale. Animal Health Research Reviews 2: 163-174.

Domingos A et al., 2013. Approaches towards tick and tick-borne diseases control. Revista da Sociedade Brasileira de Medicina Tropical 46: 265-269.

Durrani AZ et al., 20o8. Prevalence of Theileriosis in buffaloes and detection through blood smear examination and polymerase chain reaction test in district Lahore. Journal of Animal and Plant Sciences 18: 2-3.

Durrani HZ, 1992. A study on the taxonomy and bionomics of genus Haemaphysalis in domestic animals. M.Sc. Thesis, College of Veterinary Sciences, Lahore, Pakistan.

Edney EB, 1977. Water Balance in Land Arthropods. Springer-Verlag, Berlin, Germany.

Elhaig et al., 2016. Molecular confirmation of Trypanosoma evansi and Babesia bigemina in cattle from lower Egypt. Pakistan Veterinary Journal 36: 409-414.

Estrada-Pena A and Mans BJ, 2014. Tick-induced paralysis and toxicoses. In: Sonenshine DE Roe RM (editors), Biology of Ticks, Volume 2, Second Edition. Oxford University Press, Oxford, UK;pp: 313-332.

Estrada-Pena A and De la Fuente J, 2014. The ecology of ticks and epidemiology of tick-borne viral diseases. Antiviral Research 108: 104-128.

Estrada-Pena et al., 20o8. Changes in climate and their suitability for the ticks Amblyomma hebraeum and Amblyomma variegatum (Ixodidae) in Zimbabwe (1974-1999). Veterinary Parasitology 151: 256-267.

Estrada-Pena et al., 2013a. Research on the ecology of ticks and tick-borne pathogens-methodological principles and caveats. Frontiers in Cellular and Infection Microbiology 3: 29.

Estrada-Pena et al., 2013b. Factors driving the circulation and possible expansion of Crimean-Congo haemorrhagic fever virus in the western Palearctic. Journal of Applied Microbiology 114: 278-286. 
Farooqi et al., 2017. Distribution of Ixodid tick species and associated risk factors in temporal zones of Khyber Pakhtunkhwa Province. Pakistan. Pakistan Journal of Zoology 49: 2011-2017.

Farooqi et al., 2017. Molecular epidemiology of Babesia bovis in bovine of Khyber Pakhtunkhwa, Pakistan. Pakistan Veterinary Journal 37: 275-280.

Fawcett et al., 1986. The cell biology of the Ixodid tick salivary gland. In: Sauer JR Hair JA (editors), Morphology, Physiology and Behavioral Biology of Ticks. Ellis Horwood Ltd, pp: 22-45.

Felz MW and Durden LA, 1999. Attachment sites of four tick species (Acari, Ixodidae) parasitizing humans in Georgia and South Carolina. Journal of Medical Entomology 36:.361-364.

Fontaine et al., 2011. Implication of haematophagous arthropod salivary proteins in host-vector interactions. Parasites \& Vectors 4: 187.

Francischetti et al., 2009. The role of saliva in tick feeding. Frontiers in Bioscience 14: 2051-2088.

Friedhoff KT, 1990. Interaction between parasite and tick vector. International Journal of Parasitology 20: 525535.

Gaede K and Knulle W, 1997. On the mechanism of water vapours orption from unsaturated atmospheres by ticks. Journal of Experimental Biology 200: 1491-1498.

Ghafar et al., 2020. Exploring the prevalence and diversity of bovine ticks in five agro-ecological zones of Pakistan using phenetic and genetic tools. Ticks and Tick-borne Diseases 11: 101472.

Ghosh et al., 2006. Control of ticks of ruminants, with special emphasis on livestock farming systems in India: Present and future possibilities for integrated control-a review. Experimental and Applied Acarology 40: 49-66.

Gordon JR and Allen JR, 1979. The basophil response in blood and bone marrow of tick infested guinea pigs. Canadian Journal of Comparative Medicine 43: 380-383.

Grandjean O and Aeschlimann A, 1973. Contribution to the study of digestion in ticks: Histology and fine structure of the midgut ephithelium of Ornithodorus moubata, Murray (Ixodoidea, Argasidae). Acta Tropica 30: 193-212.

Gray et al., 2016. Diapause in ticks of the medically important Ixodes ricinus species complex. Ticks and Tick-Borne Diseases 7: 992-1003.

Gray JS, 1998. The ecology of ticks transmitting Lyme Borreliosis. Experimental and Applied Acarology 22: 249-258.

Gregson J 1960. Morphology and functioning of the mouthparts of Dermacentor andersoni Stiles. Part II. The feeding mechanism in relation to the host. Acta Tropica 17: 72-79.

Guglielmone et al., 2014. The hard ticks of the world (Acari: Ixodida: Ixodidae). Springer, Amsterdam, the Netherlands.

Hartemink et al., 20o8. The basic reproduction number for complex disease systems: Defining Ro for tickborne infections. The American Naturalist 171: 743754 .
Hassan et al., 2013. The prevalence and intensity of Amblyomma javanense infestation on Malayan pangolins (Manis javanica Desmarest) from Peninsular Malaysia. Acta Tropica 126: 142-145.

Hatwick et al., 1978. Fatal Rocky Mountain spotted fever. The Journal of American Medical Association 240: 1499-1503.

Hoogstraal H, 1979. The epidemiology of tick-borne Crimean-Congo hemorrhagic fever in Asia, Europe, and Africa. Journal of Medical Entomology 15: 307-417.

Iqbal et al., 2013. Frequency distribution of hard ticks (Acari: Ixodidae) infesting bubaline population of district Toba Tek Singh, Punjab, Pakistan. Parasitology Research 112: 535-541.

Jabbar et al., 2015. Tick-borne diseases of bovines in Pakistan: Major scope for future research and improved control. Parasites \& Vectors 8: 283.

Jongejan F and Uilenberg G, 2004. The global importance of ticks. Parasitology 129: 3-14.

Jouda et al., 2004. Ixodes ricinus density, and distribution and prevalence of Borrelia burgdorferi sensu lato infection along an altitudinal gradient. Journal of Medical Entomology 41: 162-169.

Kahl et al., 2002. Ecological research on Borrelia burgdorferi sensu lato: Terminology and some methodological pitfalls. In: Gray JS Kahl O Lane RS Stanek G (editors). Lyme Borreliosis: Biology, Epidemiology and Control. CABI Publishing, New York, USA; pp: 29-46.

Kahl O and Knülle W, 1988. Water vapour uptake from subsaturated atmosphere by engorged immature Ixodid ticks. Experimental and Applied Acarology 4: $73-88$.

Karim et al., 2017. A study of ticks and tick-borne livestock pathogens in Pakistan. PLoS Neglected Tropical Diseases 11: eooo5681.

Kaufman WR, 2010. Ticks: Physiological aspects with implications for pathogen transmission. Ticks and Tick-Borne Diseases 1: 11-22.

Kaufman WR and Phillips JE, 1973. Ion and water balance in the Ixodid tick, Dermacentor andersoni. II. Routes of ion and water excretion. Journal of Experimental Biology 58: 523-536.

Kemp et al., 1982. Tick attachment and feeding: Role of the mouthparts, feeding apparatus, salivary gland secretions and the host response. In: Obenchain FD Galun R (editors). Physiology of Ticks. Pergamon Press, Elmsford, pp: 119-168.

Khan IS, 1967. A study on the taxonomy and bionomics of Hyalomma spp. Koch, 1844. M.Sc. Thesis, Faculty of Veterinary Science, University of Agriculture, Faisalabad, Pakistan.

Knulle W and Rudolph D, 1982. Humidity relationships and water balance of ticks. In: Obenchain FD, Galun R (editors), The Physiology of Ticks. Pergamon Press, pp: 43-70.

Kocan et al., 2010. The natural history of Anaplasma marginale. Veterinary Parasitology 167: 95-107.

Koch HG and Sauer JR, 1984. Quantity of blood ingested by four species of hard ticks (Acari: Ixodidae) fed on 
domestic dogs. Annals of the Entomological Society of America 77: 142-146.

Kosar MH, 1965. Taxonomy and bionomics of the species of genus Rhipichephalus. M.Sc. Thesis, Department of Veterinary Parasitology, University of Agriculture, Faisalabad, Pakistan.

Krinsky WL, 1983. Dermatoses associated with the bites of mites and ticks (Arthropoda: acari). International Journal of Dermatology 22: 75-91.

Lane et al., 1999. Life history of Ixodes (Ixodes) jellisoni (Acari: Ixodidae) and its vector competence for Borrelia burgdorferi sensu lato. Journal of Medical Entomology 36: 329-340.

Lugaj et al., 2014. Serological survey of Crimean-congo Hemorrhagic fever virus in cattle in Berat and Kolonje, Albania. Albanian Journal of Agricultural Sciences. Sp. Ed. pp. 325-328.

Maddrell SHP, 1981. Characteristics of epithelial transport in insect malpighian tubules. In: Bronner $F$, Kleinzeller A (editors), Current Topics in Membranes and Transport. Volume 14. Academic Press, New York, USA; pp: 427-463.

Mans BJ, 2014. Heme processing and the evolution of hematophagy, pp. 220-239. In: Sonenshine DE \& Roe RM (editors), Biology of Ticks. Volume 1, Second Edition, Oxford University Press, New York, USA.

Mans BJ, 2011. Evolution of vertebrate hemostatic and inflammatory control mechanisms in blood-feeding arthropods. Journal of Innate Immunity 3: 41-51.

Mattioli et al., 1997. Seasonal prevalence of ticks and tick transmitted haemoparasites in traditionally managed N'Dama cattle with reference to strategic tick in Gambia. Medical and Veterinary Entomology 11: 342348.

McGarry JW, 2011. Travel and disease vector ticks. Travel Medicine and Infectious Disease 9: 49-59.

Mondal et al., 2013. Upcoming of the integrated tick control program of ruminants with special emphasis on livestock farming system in India. Ticks and Tickborne Diseases 4: 1-10.

Needham GR and Teel PD, 1986. Water balance by ticks between blood meals. In: Sauer JR, Hair JA (editors), Morphology, Physiology and Behavioral Biology of Ticks. Ellis Horwood Ltd, pp: 100-151.

Norval et al., 1994. Factors affecting the distribution of ticks Amblyomma hebraeum and A. variegatum in Zimbabwe: Implications of reduced acaricide usage. Experimental and Applied Acarology 18: 383-407.

Nyangiwe et al., 2011. Ticks on pastures and on two breeds of cattle in the Eastern Cape Province, South Africa. Onderstepoort Journal of Veterinary Research 78: 1-9.

Nyangiwe et al., 2013. Displacement of Rhipicephalus decoloratus by Rhipicephalus microplus (Acari: Ixodidae) in the Eastern Cape Province, South Africa. Experimental and Applied Acarology 61: 371-382.

Pfäffle et al., 2013. The ecology of tick-borne diseases. International Journal of Parasitology 43: 1059-1077.

Rajput et al., 2005. Comparative study of Anaplasma parasites in tick carrying buffaloes and cattle. Journal of Zhejiang University Science 11: 1057-1062.
Rehman et al., 2017. Distribution of ticks infesting ruminants and risk factors associated with high tick prevalence in livestock farms in the semi-arid and arid agro-ecological zones of Pakistan. Parasites \& Vectors 10: 190 .

Reik RF, 1962. Studies on the reaction of animals to infestation with ticks. VI. Resistance of cattle to infestation with the tick, Boophilus microplus (Canestrini). Australian Journal of Agricultural Research 13: 532-550.

Rudolph D and Knulle W, 1974. Site and mechanism of water vapour uptake from the atmosphere in Ixodid ticks. Nature 149: $84-85$.

Ruiz-Fonsa F and Gilbert L, 2010. The role of deer as vehicles to move ticks, Ixodes ricinus, between contrasting habitats. International Journal of Parasitology 40: 1013-1020.

Sajid et al., 2008. Point prevalence of hard ticks (Ixodids) infesting domestic ruminants of lower Punjab, Pakistan. International Journal of Agriculture and Biology 10: 349-351.

Sajid et al., 2009. Prevalence and associated risk factors for bovine tick infestation in two districts of lower Punjab, Pakistan. Preventive Veterinary Medicine 92: 386-391.

Schermer S, 1967. The Blood Morphology of Laboratory Animals. F.A. Davis, Philadelphia, PA, USA, 200 pp.

Schroder B and Reilly BK, 2013. A comparison between tick species collected in a controlled and control free area on a game ranch in South Africa. Journal of the South African Veterinary Association 84: E1-5.

Sibhatu et al., 2015. Production diversity and dietary diversity in small holder farm households. Proceedings of the National Academy of Sciences of the United States of America 112: 10657-10662.

Sigg et al., 2010. An alignment approach for context prediction tasks in ubicomp environments. IEEE Pervasive Computer 9: 90-97.

Smith ER and Parker DM, 2010. Tick communities at the expanding wildlife/cattle interface in the Eastern Cape Province, South Africa: Implications for Corridor disease. Journal of the South African Veterinary Association 81: 237-240.

Sojka et al., 2016. Multienzyme degradation of host serum albumin in ticks. Ticks and Tick-Borne Diseases 7: 604-613.

Stone et al., 1989. Tick/host interactions for Ixodes holocyclus: Role, effects, biosynthesis and nature of its toxic and allergenic oral secretions. Experimental and Applied Acarology 7: 59-69.

Suarez CE and Noh S, 2011. Emerging perspectives in the research of bovine Babesiosis and Anaplasmosis. Veterinary Parasitology 180: 109-125.

Sutherst RW and Wilson LJ, 1986. Tropical legumes and their ability to immobilize and kill cattle ticks. In: Juniper BE, Southwood TRE (editors), Insects and the Plant Surface. Edward and Arnold, London, UK, pp: 185-194. 
Tatchell RJ and Bennett GF, 1969. Boophilus microplus: Antihistaminic and tranquilizing drugs and cattle resistance. Experimental Parasitology 25: 57-81.

Tønnesen et al., 2004. Displacement of Boophilus decoloratus by Boophilus microplus in the Soutpansberg region, Limpopo province, South Africa. Experimental and Applied Acarology 32: 199-208.

Traub-Dargatz J et al., 2010. Equine Piroplasmosis. Proceedings of the 56th Annual Convention of the American Association of Equine Practitioners. Baltimore, Maryland, USA, 4-8 December 2010. Pp: 1-11.

Verissimo et al., 2002. Haircoat characteristics and tick infestation on Gyr (Zebu) and crossbred (Holstein Gyr) cattle. Archivio Zootechnie 51: 389-392.

Wall R and Shearer D, 20o1. Veterinary ectoparasites. Biology, pathology and control. 2nd Edition. Blackwell Science Ltd, Oxford, UK, 304 pp.

Wen et al., 2016. Rapid and sensitive diagnosis of cattle Anaplasmosis by loop-mediated isothermal amplification (LAMP). Pakistan Veterinary Journal 36: 174-178.
Wikel SJ, 1982. Histamine content of tick attachment sites and the effect of $\mathrm{H}_{1}$ and $\mathrm{H}_{2}$ histamine antagonists on the expression of resistance. Annals of Tropical Medicine and Parasitology 76: 179-185.

Willadsen et al., 1979. The relation between histamine concentration, histamine sensitivity, and the resistance of cattle to the tick, Boophilus microplus. Z Parasitenkd 59: 87-94.

Yoder et al., 2006. Developmental profiles in tick water balance with a focus on the new Rocky Mountain spotted fever vector, Rhipicephalus sanguineus. Medical and Veterinary Entomology 20:365-372.

Zia et al., 2011. Dairy development in Pakistan. Food and Agriculture Organization of the United Nations (FAO), Rome, Itly.

Zulfiqar et al., 2012. Detection of Babesia bovis in blood samples and its effect on the hematological and serum biochemical profile in large ruminants from Southern Punjab. Asian Pacific Journal of Tropical Biomedicine 1: 104-108. 